\title{
BMJ Open Private or shared room? A nationwide questionnaire survey on bereaved family members' perceptions of where patients spend their last days
}

\author{
Hiroyuki Otani (D) , ${ }^{1}$ Tatsuya Morita (D) , ${ }^{2}$ Naoko Igarashi, ${ }^{3}$ Yasuo Shima, ${ }^{4}$ \\ Mitsunori Miyashita ${ }^{3}$
}

To cite: Otani H, Morita T, Igarashi N, et al. Private or shared room? A nationwide questionnaire survey on bereaved family members' perceptions of where patients spend their last days. BMJ Open 2022;12:e055942. doi:10.1136/ bmjopen-2021-055942

- Prepublication history and additional supplemental material for this paper are available online. To view these files, please visit the journal online (http://dx.doi.org/10.1136/ bmjopen-2021-055942).

Received 04 August 2021 Accepted 28 January 2022

\section{Check for updates}

(C) Author(s) (or their employer(s)) 2022. Re-use permitted under CC BY-NC. No commercial re-use. See rights and permissions. Published by BMJ.

${ }^{1}$ Palliative Care Team, and Palliative and Supportive Care, National Hospital Organization Kyushu Cancer Center, Fukuoka, Fukuoka, Japan

${ }^{2}$ Palliative and Supportive Care, Palliative Care Team, and Seirei Hospice, Seirei Mikatahara Hospital, Hamamatsu, Shizuoka, Japan

${ }^{3}$ Palliative Nursing, Health Sciences, Tohoku University Graduate School of Medicine, Sendai, Miyagi, Japan

${ }^{4}$ Palliative Medicine, Tsukuba Medical Center Hospital, Tsukuba, Ibaraki, Japan

Correspondence to Dr Hiroyuki Otani; cas60020@pop21.odn.ne.jp

\section{ABSTRACT}

Background Where patients receive end-of-life care influences their quality of life.

Objectives To clarify the effects of staying in a private or shared room in inpatient hospices.

Design A part of a Japanese multicentre survey to evaluate the quality of end-of-life care.

Setting/participants 779 bereaved families whose relatives who died from cancer in inpatient hospices. Measurements The primary outcome was familyperceived need for improvement in environment-related professional care. Secondary end-points included: family satisfaction, environment-related family perception, and quality of death and dying (Good Death Inventory: GDI).

Results 574 responded (73.7\%). 300 patients were in a private room from admission to discharge, 47 were in a shared room less than $50 \%$ of the time, and the remaining 85 were in a shared room $50 \%$ or more. There were significant differences in the need for improvement in shared (vs private) rooms, and in favour of private rooms for: 'privacy was protected', 'easy for visitors to visit', 'could discuss sensitive issues with medical staff without concern', and 'could visit at night.', as well as 'living in calm circumstances' and 'spending enough time with family' of the GDI. Contrarily, significant differences were found in favour of shared rooms for: 'the patient could interact with other patients'. There was no significant difference in family satisfaction and total score of GDI. Conclusion There are the advantages and disadvantages of spending one's final days in a private or shared room, and adjusting rooms according to patients and their families' values is necessary.

\section{INTRODUCTION}

The environment in which patients spend time at the end of their lives affects their quality of life. ${ }^{1}$ The effects of spending time in a private or shared room in hospital settings have been examined previously. Private rooms were shown to offer greater privacy and dignity and less noise, improve sleep, ${ }^{2}$ provide better access to visitors and family members, ${ }^{3}$ and foster superior physician-patient communication (eg, longer conversations, easier to
Strengths and limitations of this study

The current study was the first large-scale study to examine the perspectives of bereaved relatives of deceased patients and the effects of spending time in private and shared rooms on patients in inpatient hospices in Japan.

- The response rate was $75 \%$, which was a generally moderate response rate.

- This study examined bereaved family members' perceptions; there was no input from the patients themselves.

- In this study, the validity and reliability of the familyperception questionnaires were not tested.

respond to patients' questions, and greater empathy from physicians) as compared with shared rooms. ${ }^{4}$ However, patients in shared rooms were less likely to feel lonely, as they could talk to their roommates and had peers with the same disease. ${ }^{35}$

Therefore, while private and shared rooms each offer advantages, patients' preferences are diverse. ${ }^{5-7}$ Additionally, preferences for private and shared rooms differ according to historical background: only $37 \%$ of elderly inpatients desired a private room in 2008, while $85 \%$ preferred admission to a private room in 2013, and many reported not feeling lonely in a private room. ${ }^{8}$ Moreover, consideration of whether a patient should be in a private or shared room, depending on physical symptoms (eg, diarrhoea), and his or her medical condition soon before death, is necessary. ${ }^{3910}$

Some studies have examined patients' intention to stay in private or shared rooms in palliative care wards abroad ${ }^{37}$; however, they have been limited to small groups of patients. Moreover, it would be useful to clarify the advantages and disadvantages of private and shared rooms for inpatients in hospices 
from the perspective of bereaved relatives and consider supportive measures in each setting. The purpose of this study was to determine the impact of staying in private or shared rooms during end-of-life care in an inpatient hospice setting.

\section{MATERIALS AND METHODS}

This study was part of a nationwide survey-the Japan Hospice and Palliative Care Evaluation Study (J-HOPE 2016) - which evaluated the quality of end-of-life care throughout Japan. ${ }^{11}$ A multicentre questionnaire survey was used to target bereaved relatives of patients with cancer who had died in palliative care units/inpatient hospices. We mailed questionnaires to bereaved relatives in May 2016 and repeated this process for non-responding families in June 2016. The completion and return of the questionnaire were regarded as consent to participate in the study, and relatives who did not wish to participate were asked to return the uncompleted questionnaire.

\section{Setting and participants}

Primary physicians identified potential participants according to the following inclusion criteria: (1) death of an adult family member who had died of cancer (one relative was selected for each patient), (2) aged $\geq 20$ years, (3) could complete a self-report questionnaire and (4) aware of their malignant diagnosis. The exclusion criteria were: (1) unable to complete the questionnaire (ie, because of dementia, cognitive failure, psychiatric illness, language difficulty, or visual loss), (2) patients' treatment-associated death or death in an intensive care unit, (3) unavailability, (4) patients' receipt of palliative care services for $<3$ days, and (5) serious psychological distress as confirmed by the primary physician. As in previous studies, ${ }^{12} 13$ the final criterion was adopted based on the assumption that primary physicians could identify relatives with the potential to experience serious psychological effects, given the aim of the study; no formal criteria or psychiatric screening were used. Following a previous study, ${ }^{11}$ relatives were surveyed 6-12 months after patients' deaths. Questionnaires were then administered to 779 bereaved individuals whose relatives had spent time in an inpatient hospice, and 574 returned completed questionnaires ( $73 \%$ recovery rate).

\section{Questionnaire}

The questionnaire was developed by the authors, based on a literature review ${ }^{1-10}$ and discussion (see online supplemental file 1). The face validity of the questionnaire was confirmed via a pilot test involving five bereaved family members and five physicians.

The primary outcome of the study was familyperceived need for the improvement of professional care related to room environment. Because of a lack of validated instruments, these outcome parameters were developed based on previous surveys. ${ }^{13-17}$ The need for improvement was evaluated according to responses to the following: 'How much improvement in care do you think is necessary based on room environment (shared or private room)?' Responses were provided using a 4-point scale as follows: 1 = 'no need for improvement', 2 = 'need for some improvement', 3 = 'need for considerable improvement', and $4=$ 'need for great improvement'.

Secondary end-points were (1) family satisfaction with end-of-life care, (2) family perception related to the environment, and (3) quality of death and dying. Family satisfaction was rated using a one-item 6-point Likert-type satisfaction scale from not satisfied at all (1) to completely satisfied (6). Family perceptions related to the room environment were investigated using eight items evaluated according to the extent of participants' agreement with the following statements, with responses provided using a 4-point Likert-type scale ranging from 1 (disagree) to 4 (agree): 'privacy was protected', 'it was easy for visitors to visit when they wished to do so', 'I could discuss sensitive issues with medical staff without concern', 'I could visit at night when I wished to do so', 'The patient could interact with other patients', 'I could interact with my family member and other families', 'The patient may often feel lonely', and 'I worried that the interactions between the patient and medical staff were limited'. Quality of death and dying was evaluated by using the Good Death Inventory. ${ }^{18-20}$ This measure was developed on the basis of qualitative interviews and a large-scale quantitative study; it has 18 domains representing concepts important to good death in Japanese patients with cancer. ${ }^{18} 19$ In this study, we used the short version of the Good Death Inventory, which consists of 10 core items and has sufficient reliability and validity. ${ }^{19}$ The 10 core items evaluate the attributes that Japanese people consistently rate as important: physical and psychological comfort, living in a favourite place, maintaining hope and pleasure, a good relationship with medical staff, not feeling like a burden to others, maintaining a good relationship with the family, independence, environmental comfort, being respected as an individual, and a feeling of fulfilment at life completion. Bereaved family members evaluated each attribute using a seven-point Likert scale (1: absolutely disagree, 2: disagree, 3: somewhat disagree, 4: unsure, 5: somewhat agree, 6: agree, and 7: absolutely agree). In addition, we measured three items related to room environment to understand family experience: 'the patient was in a large room; however, shortly before he/she died, he/ she moved to a private room'; 'I would have liked to see the patient end up in a private room; but he/she died in a large room'; and 'the patient had to use a private room, which was costly because the shared room was not available for a while'.

Whether a patient used a private room or shared room was assessed by asking about the percentages of time for which they used a private room or shared room $(0 \%$ to $100 \%)$. In addition, we asked family members to report the following demographic data: age, sex, 
Table 1 Place of care and the characteristics of patients and their relatives $(N=432)$

\begin{tabular}{|c|c|c|c|c|c|c|c|}
\hline Patients & \multicolumn{2}{|c|}{$\begin{array}{l}\text { A private room for } \\
100 \% \text { of the time } \\
(n=300)\end{array}$} & \multicolumn{2}{|c|}{$\begin{array}{l}\text { A shared room for less } \\
\text { than } 50 \% \text { of the time } \\
(n=47)\end{array}$} & \multicolumn{2}{|c|}{$\begin{array}{l}\text { A shared room for } 50 \% \text { or } \\
\text { more of the time }(n=85)\end{array}$} & P value \\
\hline $\begin{array}{l}\text { Age in years (mean and } \\
\text { SD) }\end{array}$ & 74.1 & 11.8 & 76.5 & 10.4 & 73.2 & 10.9 & 0.16 \\
\hline \multicolumn{8}{|l|}{ Sex } \\
\hline Male & 151 & $50.3 \%$ & 24 & $51.0 \%$ & 43 & $50.5 \%$ & 0.99 \\
\hline Female & 148 & $49.3 \%$ & 23 & $48.9 \%$ & 42 & $49.4 \%$ & \\
\hline Primary cancer site & & & & & & & 0.32 \\
\hline Lung & 76 & $25.3 \%$ & 6 & $12.8 \%$ & 18 & $21.1 \%$ & \\
\hline $\begin{array}{l}\text { Oesophagus and } \\
\text { stomach }\end{array}$ & 45 & $15 \%$ & 12 & $25.5 \%$ & 9 & $10.6 \%$ & \\
\hline Colon and rectum & 39 & $13 \%$ & 8 & $17.0 \%$ & 16 & $18.8 \%$ & \\
\hline Pancreas & 32 & $10.7 \%$ & 3 & $6.4 \%$ & 6 & $7.1 \%$ & \\
\hline Gall bladder & 15 & $5.0 \%$ & 3 & $6.4 \%$ & 8 & $9.4 \%$ & \\
\hline Brain, head, and neck & 15 & $5.0 \%$ & 4 & $8.5 \%$ & 6 & $7.1 \%$ & \\
\hline Liver & 14 & $4.7 \%$ & 0 & $0 \%$ & 4 & $4.7 \%$ & \\
\hline Breast & 21 & $7.0 \%$ & 0 & $0 \%$ & 0 & $0 \%$ & \\
\hline Kidney and bladder & 9 & $3.0 \%$ & 4 & $8.5 \%$ & 5 & $5.9 \% \%$ & \\
\hline Uterus and ovary & 13 & $4.3 \%$ & 1 & $2.1 \%$ & 3 & $3.5 \%$ & \\
\hline Prostate & 5 & $1.7 \%$ & 1 & $2.1 \%$ & 3 & $3.5 \%$ & \\
\hline Blood/lymph nodes & 3 & $1.0 \%$ & 1 & $2.1 \%$ & 3 & $3.5 \%$ & \\
\hline Other & 12 & $4.0 \%$ & 4 & $8.5 \%$ & 4 & $4.7 \%$ & \\
\hline $\begin{array}{l}\text { Hospitalisation duration in } \\
\text { days (mean and SD) }\end{array}$ & 43.9 & 62.2 & 40.0 & 53.2 & 34.5 & 46.3 & 0.68 \\
\hline \multicolumn{8}{|l|}{ Family caregivers } \\
\hline $\begin{array}{l}\text { Age in years (mean and } \\
\text { SD) }\end{array}$ & 62.6 & 11.7 & 58.6 & 11.7 & 60.5 & 12.1 & 0.08 \\
\hline \multicolumn{8}{|l|}{ Sex } \\
\hline Male & 94 & $31.3 \%$ & 17 & $36.1 \%$ & 28 & $32.9 \%$ & 0.77 \\
\hline Female & 201 & $67 \%$ & 29 & $61.7 \%$ & 56 & $65.9 \%$ & \\
\hline Relationship to patient & & & & & & & 0.77 \\
\hline Spouse & 128 & $42.7 \%$ & 13 & $27.7 \%$ & 35 & $41.1 \%$ & \\
\hline Child & 115 & $38.3 \%$ & 27 & $57.4 \%$ & 32 & $37.6 \%$ & \\
\hline Sibling & 20 & $6.7 \%$ & 1 & $2.1 \%$ & 6 & $7.1 \%$ & \\
\hline Parent & 8 & $2.7 \%$ & 2 & $4.2 \%$ & 1 & $1.1 \%$ & \\
\hline Other & 24 & $8.0 \%$ & 4 & $8.5 \%$ & 10 & $11.8 \%$ & \\
\hline
\end{tabular}

Values are mean \pm SD, or $n(\%)$. Total percentages do not equal $100 \%$ because of missing values.

and relationship to the patient; patients' age, sex, and tumour sites; and duration of patients' stay in an inpatient hospice.

\section{Statistical analyses}

First, we classified the responses into three groups: (1) the families of patients who were in a private room from admission to discharge (used a private room 100\% of the time), (2) the families of patients who were in a shared room less than $50 \%$ of the time, and (3) the families of patients who were in a shared room $50 \%$ or more of the time. We compared the need for improvement, family satisfaction and the family perceptions and quality of death and dying between the groups using analyses of variance (Tukey's post-hoc test) or $\chi^{2}$ tests, where appropriate.

Meanwhile, $p$ values $<0.05$ were regarded as significant, and we decided not to adjust for multiple comparisons 
Table 2 Comparison of the necessity for improvement and family perceptions based on patients' room

\begin{tabular}{|c|c|c|c|c|c|c|c|c|}
\hline & \multicolumn{2}{|c|}{$\begin{array}{l}\text { A private room for } \\
100 \% \text { of the time } \\
(n=300, A)\end{array}$} & \multicolumn{2}{|c|}{$\begin{array}{l}\text { A shared room for } \\
\text { less than } 50 \% \text { of } \\
\text { the time }(n=47, B)\end{array}$} & \multicolumn{2}{|c|}{$\begin{array}{l}\text { A shared room for } \\
50 \% \text { or more of } \\
\text { the time }(n=85, C)\end{array}$} & \multirow[b]{2}{*}{$P$ value } & \multirow{2}{*}{$\begin{array}{l}\text { P value } \\
\text { (intergroup) }\end{array}$} \\
\hline & Mean & SD & Mean & SD & Mean & SD & & \\
\hline $\begin{array}{l}\text { The necessity for } \\
\text { improvement of professional } \\
\text { care related to the room } \\
\text { environment (ranging from 1: } \\
\text { no need for improvement to } 4 \text { : } \\
\text { need for great improvement) }\end{array}$ & 1.3 & 0.51 & 1.7 & 0.77 & 1.5 & 0.73 & $<0.001$ & $\begin{array}{l}\text { A versus } B \\
(<0.001) \\
\text { A versus C (.019) }\end{array}$ \\
\hline $\begin{array}{l}\text { Satisfaction level with end-of- } \\
\text { life care (ranging from 1: not } \\
\text { satisfied at all to 6: completely } \\
\text { satisfied) }\end{array}$ & 4.9 & 1.1 & 5.0 & 1.0 & 4.7 & 1.3 & 0.11 & - \\
\hline $\begin{array}{l}\text { It was easy for visitors to visit } \\
\text { when they wished to do so }\end{array}$ & 3.8 & 0.41 & 3.7 & 0.64 & 3.4 & 0.81 & $<0.001$ & $\begin{array}{l}\text { B versus C } \\
(<0.001) \\
\text { A versus C } \\
(<0.001)\end{array}$ \\
\hline $\begin{array}{l}\text { I could discuss sensitive } \\
\text { issues with medical staff } \\
\text { without concern }\end{array}$ & 3.7 & 0.54 & 3.5 & 0.72 & 3.3 & 0.82 & $<0.001$ & $\begin{array}{l}\text { A versus } C \\
(<0.001)\end{array}$ \\
\hline $\begin{array}{l}\text { I could visit at night when I } \\
\text { wished to do so }\end{array}$ & 3.8 & 0.39 & 3.8 & 0.53 & 3.5 & 0.70 & $<0.001$ & $\begin{array}{l}\text { A versus } C \\
(<0.001)\end{array}$ \\
\hline $\begin{array}{l}\text { The patient could interact with } \\
\text { other patients }\end{array}$ & 1.6 & 0.93 & 1.6 & 0.88 & 2.0 & 1.0 & 0.001 & $\begin{array}{l}B \text { versus } C(.039) \\
\text { A versus C } \\
(<0.001)\end{array}$ \\
\hline
\end{tabular}

owing to the exploratory nature of this study. All statistical analyses were performed using SPSS V.19.0 (SPSS).

\section{Patient and public involvement}

Patients and the public were not involved in this study. However, the face validity of the questionnaire was confirmed via a pilot test involving five bereaved family members.

\section{RESULTS}

Among the 574 responding individuals, 142 were excluded owing to missing values in primary end-points and information about use of private or shared rooms. Thus, 432 responses were analysed.
The background characteristics of patients and their relatives are presented in table 1 . Three-hundred patients $(69.4 \%)$ were in a private room from admission to discharge (ie, $100 \%$ of the time), 47 patients $(10.9 \%$ ) were in a shared room less than $50 \%$ of the time, and the remaining 85 patients $(19.7 \%)$ were in a shared room $50 \%$ or more of the time (table 1 ).

The results of the primary and secondary outcomes are illustrated in table 2 . Of the 432 valid responses to the question, 'how much improvement in care do you think is necessary based on room environment (shared or private room)?' 284 (65.7\%) participants stated that there was no need for improvement, $127(29.4 \%)$ stated that there was a need for some improvement, 17 (3.9\%) stated that there was a need for considerable improvement, and 4 
Table 3 Comparison of the Good Death Inventory (quality of death and dying) and family perceptions based on patients' room

\begin{tabular}{|c|c|c|c|c|c|c|c|c|}
\hline & \multicolumn{2}{|c|}{$\begin{array}{l}\text { A private room for } \\
100 \% \text { of the time } \\
(n=300, A)\end{array}$} & \multicolumn{2}{|c|}{$\begin{array}{l}\text { A shared room for } \\
\text { less than } 50 \% \text { of the } \\
\text { time }(n=47, B)\end{array}$} & \multicolumn{2}{|c|}{$\begin{array}{l}\text { A shared room for } \\
50 \% \text { or more of the } \\
\text { time }(n=85, C)\end{array}$} & \multirow[t]{2}{*}{$P$ value } & \multirow[t]{2}{*}{$\begin{array}{l}\text { P value } \\
\text { (intergroup) }\end{array}$} \\
\hline & Mean & SD & Mean & SD & Mean & SD & & \\
\hline Total score & 48 & 7.6 & 50 & 7.3 & 47 & 8.6 & 0.10 & - \\
\hline $\begin{array}{l}\text { Being valued as a } \\
\text { person }\end{array}$ & 6.1 & 0.86 & 6.0 & 1.0 & 5.9 & 1.1 & 0.30 & - \\
\hline $\begin{array}{l}\text { Living in calm } \\
\text { circumstances }\end{array}$ & 5.4 & 1.1 & 5.5 & 1.0 & 5.0 & 1.2 & $<0.001$ & $\begin{array}{l}B \text { versus } C(.022) \\
A \text { versus } C \\
(<0.001)\end{array}$ \\
\hline Trusting physician & 5.4 & 1.2 & 5.2 & 1.1 & 5.4 & 1.1 & 0.60 & - \\
\hline $\begin{array}{l}\text { Being free from } \\
\text { physical distress }\end{array}$ & 5.2 & 1.2 & 5.1 & 1.3 & 5.0 & 1.3 & 0.37 & - \\
\hline $\begin{array}{l}\text { Spending enough } \\
\text { time with one's } \\
\text { family }\end{array}$ & 5.0 & 1.3 & 5.1 & 1.3 & 4.6 & 1.4 & 0.028 & $A$ versus $C(.024)$ \\
\hline $\begin{array}{l}\text { Being able to stay at } \\
\text { one's favourite place }\end{array}$ & 4.7 & 1.4 & 5.0 & 1.2 & 4.5 & 1.6 & 0.11 & - \\
\hline $\begin{array}{l}\text { Feeling that one's } \\
\text { life was completed }\end{array}$ & 4.6 & 1.6 & 5.2 & 1.4 & 4.5 & 1.9 & 0.064 & - \\
\hline $\begin{array}{l}\text { Being a burden to } \\
\text { others }\end{array}$ & 4.4 & 1.5 & 4.3 & 1.6 & 4.7 & 1.4 & 0.17 & - \\
\hline $\begin{array}{l}\text { Having some } \\
\text { pleasure in daily life }\end{array}$ & 4.3 & 1.5 & 4.5 & 1.4 & 3.9 & 1.6 & 0.045 & $\begin{array}{l}\text { A versus B }(.79) \\
B \text { versus C (.091) } \\
\text { A versus C (.062) }\end{array}$ \\
\hline $\begin{array}{l}\text { Being independent } \\
\text { in daily life }\end{array}$ & 3.0 & 1.8 & 3.8 & 2.1 & 3.3 & 2.0 & 0.019 & $A$ versus $B(.024)$ \\
\hline
\end{tabular}

$(0.9 \%)$ stated that there was a need for great improvement. There was a significant difference in the need for improvement in shared (vs private) rooms $(\mathrm{p}<0.001)$. In contrast, there was no significant difference in satisfaction with end-of-life care between private and shared rooms $(\mathrm{p}=0.11)$.

Significant differences were found in favour of private (vs shared) rooms for the following specific items: 'privacy was protected' $(\mathrm{p}<0.001)$, 'it was easy for visitors to visit when they wished to do so' $(p<0.001)$, 'I could discuss sensitive issues with medical staff without concern' ( $\mathrm{p}<0.001)$, 'I could visit at night when I wished to do so' $(\mathrm{p}<0.001)$, and in the Comparison of the Good Death Inventory, 'Living in calm circumstances' $(p<0.001)$ and 'Spending enough time with one's family' $(p=0.028)$. In contrast, significant differences were found in favour of shared (vs private) rooms for the following items: 'The patient could interact with other patients' $(p=0.001)$, and in the Comparison of the Good Death Inventory, 'Being independent in daily life' ( $\mathrm{p}=0.019$ ) (table 3 ).

Participants' experiences related to moving rooms were as follows: 'the patient was in a large room; however, shortly before he/she died, he/she moved to a private room' (agree; $n=81,18.8 \%$ ); 'I would have liked to see the patient end up in a private room; but he/she died in a large room' (agree; $\mathrm{n}=37,8.6 \%$ ); and 'The patient had to use a private room, which was costly because the shared room was not available for a while' (agree; $\mathrm{n}=8,1.9 \%$ ).

\section{DISCUSSION}

The current study was the first large-scale study to examine the perspectives of bereaved relatives of deceased patients and the effects of spending time in private and shared rooms on patients in inpatient hospices in Japan. Participants were mostly satisfied with end-of-life care in both private and shared rooms; however, some improvements to professional care related to room environment are needed. There was a significant difference in the need for improvement in shared (vs private) rooms but not concerning participants' satisfaction with end-of-life care. Factors that the participants perceived as benefits of a private room included privacy, the ease in receiving visitors, and the ability to talk with medical staff. In contrast, factors that they perceived as benefits of a shared room included interacting with the patient and other patients.

This study revealed conflicting desires regarding the room environment-a private or shared room during end-of-life care in an inpatient hospice setting. For example, while a private room is suitable for some issues, 
such as the protection of privacy, a shared room is suitable for ensuring that patients do not feel lonely. Therefore, in shared rooms, it could be useful to consider setting up a separate private space that can be used by anyone at any time. Patients in private rooms were concerned that they would not be seen by medical staff; thus, certain measures, such as having medical staff visit private rooms frequently, should be considered to address this concern. Previous studies had also noted patients' concerns with loneliness $^{21}{ }^{22}$; therefore, interactions with other patients should be facilitated, and individualised considerations (eg, people, nature, sounds, memories, pets, and scents) could be useful. ${ }^{23}$

Additionally, there were significant differences in favour of private rooms for 'living in calm circumstances' and 'spending enough time with family' in the GDI. Meaningful communication (saying 'goodbye') between the patient and family members, and not their presence or absence itself, was associated with better outcomes on measures of depression and complicated grief. ${ }^{24}$ In a private room, it would have been possible to create an atmosphere in which meaningful communication (saying 'goodbye') could have occurred. In addition, home hospices scored higher on the GDI than inpatient hospices. ${ }^{25}$ Private rooms contain elements that are closer to home. ${ }^{26}$ This might explain the finding in this study that there was a significant difference in favour of private rooms for 'living in calm circumstances' and 'spending enough time with family' on the GDI. Meanwhile, there were significant differences in favour of shared rooms for 'being independent in daily life' in the GDI. In this study, significant differences were found in favour of shared rooms for 'the patient could interact with other patients'. This could be interpreted as patients with independent daily life were able to interact with other patients in shared rooms.

In this way, for patients who had to be moved to a shared room or private room because of various problems, such as physical problems peculiar to the terminal stage, psychological problems such as delirium, and financial problems such as hospitalisation costs, we believe that individual consideration of the advantages and disadvantages of spending the last days of life in a private room or shared room is effective.

The limitations of this study include: generally moderate response rate $(75 \%)$, no input from patient themselves, and no validity or reliability testing of family-perception questionnaires. Additionally, this study found that approximately $70 \%$ of patients in the inpatient hospices were placed in private rooms for the entire period from admission to discharge. Therefore, we might not have captured the views of participants whose relatives had spent much of their time in shared rooms.

\section{CONCLUSIONS}

In end-of-life care, the environment in which patients spend time affects their quality of life. ${ }^{1}$ The current findings clarified the advantages and disadvantages of spending one's final days of life in a private or shared room in an inpatient hospice. Based on these results, it is necessary to adjust the room according to the values of patients and their families.

Acknowledgements We thank all of the bereaved family members who completed the questionnaire.

Contributors Conception/design: HO; Provision of study material or patients: TM, $\mathrm{NI}$, YS and MM; Collection and/or assembly of data: $\mathrm{NI}$ and MM; Data analysis and interpretation: $\mathrm{HO}$ and TM; Manuscript writing: $\mathrm{HO}$; Final approval of manuscript: $\mathrm{HO}, \mathrm{TM}, \mathrm{NI}, \mathrm{YS}$ and MM. HO acts as a guarantor of the study.

Funding This study was part of the Japan Hospice and Palliative Care Evaluation 2016 (J-HOPE 2016) Study.

Competing interests None declared.

Patient consent for publication Not applicable.

Ethics approval Ethical and scientific validity were confirmed by the institutional review boards at all participating institutions. Each institutional review board/ ethics committee determined that informed consent was not required. This study was approved by the institutional review board/ethical review committee at the institutes with which the authors are affiliated.

Provenance and peer review Not commissioned; externally peer reviewed.

Data availability statement Data are available upon reasonable request. No data are available.

Supplemental material This content has been supplied by the author(s). It has not been vetted by BMJ Publishing Group Limited (BMJ) and may not have been peer-reviewed. Any opinions or recommendations discussed are solely those of the author(s) and are not endorsed by BMJ. BMJ disclaims all liability and responsibility arising from any reliance placed on the content. Where the content includes any translated material, BMJ does not warrant the accuracy and reliability of the translations (including but not limited to local regulations, clinical guidelines, terminology, drug names and drug dosages), and is not responsible for any error and/or omissions arising from translation and adaptation or otherwise.

Open access This is an open access article distributed in accordance with the Creative Commons Attribution Non Commercial (CC BY-NC 4.0) license, which permits others to distribute, remix, adapt, build upon this work non-commercially, and license their derivative works on different terms, provided the original work is properly cited, appropriate credit is given, any changes made indicated, and the use is non-commercial. See: http://creativecommons.org/licenses/by-nc/4.0/.

\section{ORCID iDs}

Hiroyuki Otani http://orcid.org/0000-0002-2437-4344

Tatsuya Morita http://orcid.org/0000-0002-7257-7429

\section{REFERENCES}

1 Rowlands J, Noble S. How does the environment impact on the quality of life of advanced cancer patients? A qualitative study with implications for ward design. Palliat Med 2008;22:768-74.

2 van de Glind I, de Roode S, Goossensen A. Do patients in hospitals benefit from single rooms? A literature review. Health Policy 2007;84:153-61.

3 Williams C, Gardiner C. Preference for a single or shared room in a UK inpatient hospice: patient, family and staff perspectives. BMJ Support Palliat Care 2015;5:169-74.

4 van de Glind I, van Dulmen S, Goossensen A. Physician-Patient communication in single-bedded versus four-bedded Hospital rooms. Patient Educ Couns 2008;73:215-9.

5 Pease NJF, Finlay IG. Do patients and their relatives prefer single cubicles or shared wards? Palliat Med 2002;16:445-6.

6 Florey L, Flynn R, Isles C. Patient preferences for single rooms or shared accommodation in a district general Hospital. Scott Med J 2009;54:5-8.

7 Kirk S. Patient preferences for a single or shared room in a hospice. Nurs Times 2002;98:39-41.

8 Reid J, Wilson K, Anderson KE, et al. Older inpatients' room preference: single versus shared accommodation. Age Ageing 2015;44:331-3. 
9 Hwang IC, Ahn HY, Park SM, et al. Clinical changes in terminally ill cancer patients and death within $48 \mathrm{H}$ : when should we refer patients to a separate room? Support Care Cancer 2013;21:835-40.

10 Chaudhury H, Mahmood A. Advantages and disadvantages of single versus multiple-occupancy rooms in acute care environments: a review and analysis of the literature. Environ Behav 2005;37:760-86.

11 Miyashita M, Morita T, Hirai K. Evaluation of end-of-life cancer care from the perspective of bereaved family members: the Japanese experience. J Clin Oncol 2008;26:3845-52.

12 Morita T, Miyashita M, Yamagishi A, et al. Effects of a programme of interventions on regional comprehensive palliative care for patients with cancer: a mixed-methods study. Lancet Oncol 2013;14:638-46.

13 Shinjo T, Morita T, Hirai K, et al. Care for imminently dying cancer patients: family members' experiences and recommendations. $J$ Clin Oncol 2010:28:142-8.

14 Morita T, Hirai K, Sakaguchi Y, et al. Measuring the quality of structure and process in end-of-life care from the bereaved family perspective. J Pain Symptom Manage 2004;27:492-501.

15 Morita T, Akechi T, Ikenaga M, et al. Communication about the ending of anticancer treatment and transition to palliative care. Ann Oncol 2004;15:1551-7.

16 Morita T, Ikenaga M, Adachi I, et al. Family experience with palliative sedation therapy for terminally ill cancer patients. J Pain Symptom Manage 2004;28:557-65.

17 Morita T, Akechi T, Ikenaga M, et al. Terminal delirium: recommendations from bereaved families' experiences. J Pain Symptom Manage 2007;34:579-89.
18 Miyashita M, Sanjo M, Morita T, et al. Good death in cancer care: a nationwide quantitative study. Ann Oncol 2007;18:1090-7.

19 Miyashita M, Morita T, Sato K, et al. Good death inventory: a measure for evaluating good death from the bereaved family member's perspective. J Pain Symptom Manage 2008;35:486-98.

20 Hirai K, Miyashita M, Morita T, et al. Good death in Japanese cancer care: a qualitative study. J Pain Symptom Manage 2006;31:140-7.

21 Çıracı Y, Nural N, Saltürk Z. Loneliness of oncology patients at the end of life. Support Care Cancer 2016;24:3525-31.

22 Karnick PM. Feeling Lonely: theoretical perspectives. Nurs Sci Q 2005;18:7-12.

23 Gardiner C, Geldenhuys G, Gott M. Interventions to reduce social isolation and loneliness among older people: an integrative review. Health Soc Care Community 2018;26:147-57.

24 Otani H, Yoshida S, Morita T, et al. Meaningful communication before death, but not present at the time of death itself, is associated with better outcomes on measures of depression and complicated grief among bereaved family members of cancer patients. J Pain Symptom Manage 2017;54:273-9.

25 Miyashita M, Morita T, Sato K, et al. A nationwide survey of quality of end-of-life cancer care in designated cancer centers, inpatient palliative care units, and home Hospices in Japan: the J-HOPE study. J Pain Symptom Manage 2015;50:38-47.

26 Otani $\mathrm{H}$, Morita $\mathrm{T}$, Igarashi $\mathrm{N}$, et al. A nationwide survey of bereaved family members' perception of the place patients spent their final days: is the inpatient hospice like or unlike a home? why? Palliat Med Rep 2020;1:174-8. 